\title{
ANALISIS SOFT STARTING MENGGUNAKAN ANTI PARALEL SCR UNTUK MOTOR INDUKSI 3 FASA $15 \mathrm{~kW}$ Analysis of Soft Starting using Anti Parallel SCR for 3 Phase Induction Motor $15 \mathrm{~kW}$
}

\author{
Ananda Ghufran ${ }^{1}$, I Made Ari Nrartha ${ }^{1}$, dan Sabar Nababan ${ }^{1}$ \\ ${ }^{1}$ Jurusan Teknik Elektro, Universitas Mataram. Jl. Majapahit 62, Mataram, 83125 Lombok, Indonesia \\ Email: anandaghufran@gmail.com, nrartha@unram.ac.id, nababan.sabar@gmail.com
}

\begin{abstract}
ABSTRAK
Starting dari motor induksi kapasitas besar menghasilkan arus start mencapai 5 sampai 7 kali dari arus nominal motor. Hal ini mengakibatkan drop tegangan pada sistem dan mengganggu peralatan lain yang dihubungkan pada saluran yang sama. Paper ini menggunakan simulasi MATLAB untuk analisis soft starting menggunakan anti paralel SCR pada rangkaian start motor induksi tiga fase $15 \mathrm{~kW}$. Analisis meliputi arus starting, Total Hamonic Distortion (THD) dan energi yang dikonsumsi selama starting. Rangkaian anti paralel SCR untuk mengontrol tegangan input motor induksi dengan cara memberikan pulsa trigger secara bertahap pada Gate SCR dari sudut fase $162^{\circ}$ sampai $0^{\circ}$ dalam waktu $5,10,15$, dan 20 detik. Hasil simulasi menunjukkan soft starting menggunakan anti paralel SCR dapat mengurangi arus starting menjadi $92.53 \mathrm{~A}$ untuk durasi starting 20 detik dibandingkan dengan metoda Direct On Line (DOL) yang menghasilkan arus starting 299.7 A. THD tegangan dan arus tertinggi diperoleh pada sudut fase tinggi. Konsumsi energi selama starting sangat dipengaruhi oleh durasi starting. Semakin lama durasi starting, energi yang dikonsumsi selama starting semakin besar.
\end{abstract}

Kata kunci: Anti paralel SCR, DOL, Energi , Soft starting, THD.

\section{ABSTRACT}

Starting of a large capacity induction motor produces starting current up tof 5 to 7 times of the nominal current of the motor. That results, a huge voltage drop across the system and interferes with other equipment connected to the same line. This paper utilize a MATLAB simulation for analyzing of soft starting of a 3 phase $15 \mathrm{~kW}$ induction motor using anti-parallel SCR. The analysis includes starting current, Total Hamonic Distortion (THD) and energy consumed during starting. SCR anti-parallel circuit to control the induction motor input voltage by giving trigger pulses gradually on the SCR Gate from the phase angle of 1620 to 00 within 5, 10, 15, and 20 seconds. The simulation results show that soft starting using anti-parallel SCR can reduce the starting current to 92.53 A for a starting duration of 20 seconds compared to the Direct On Line (DOL) method which produces a starting current of $299.7 \mathrm{~A}$. The highest THD voltage and current are obtained at high phase angles. Energy consumption during starting is mostly determined by the starting duration. The longer the starting duration, the greater the energy consumed by motor at the starting.period.

Key words: SCR anti-paralel, DOL, Energy, Soft Starting, THD.

\section{PENDAHULUAN}

Motor listrik sebagai penggerak sangat berperan penting dalam dunia industri. Jenis penggerak yang sering dipakai adalah motor AC khusunya motor induksi tiga fasa. Motor ini memiliki beberapa kelebihan dibandingkan motor jenis yang lain seperti kontruksi sangat sederhana, harga dan perawatan yang murah.

Permasalahan yang pasti pada motor induksi adalah pada saat motor di-start, arus starting motor dapat mencapai lima kali sampai tujuh kali dari arus nominalnya. Penomena melonjaknya arus awal saat motor induksi di-start tersebut dapat menyebabkan tejadinya drop tegangan pada pasokan tegangan. Pada pengaplikasian motor induksi dengan daya diatas $30 \mathrm{KW}$ dapat mengakibatkan penurunan tegangan sistem dan mengganggu kerja sistem peralatan lain yang terhubung dalam satu saluran [1]. 
Karena begitu luasnya penggunaan motor induksi maka banyak dilakukan berbagai penelitian untuk meningkatkan unjuk kerja dari motor induksi. Penelitianpenelitian tersebut antara lain adalah tentang metode starting motor. Beberapa metode starting tradisional motor induksi seperti metoda Direct On Line (DOL), metoda $Y-\Delta$, metoda autotrafo, dan metoda primary resistor. Disamping metoda-metoda tersebut terdapat metoda yang lebih smooth untuk mengurangi arus starting seperti metoda soft starting motor induksi.

Metode soft starting mengatur tegangan dan arus dari sumber mengalir masuk ke motor secara bertahap, sehingga motor tidak menarik arus starting yang terlalu besar. Sehingga diharapkan motor akan aman dan mempunyai umur lebih panjang [2].

Penelitian-penelitian soft starting dalam bentuk rancangan hardware sudah dilakukan menggunakan komponen TRIAC dengan mikrokontroler ATmega 8535 untuk soft starting motor tiga fase $1 \mathrm{HP}$ [3], begitupula [4] menggunakan jenis mikrokontroller Atmega328 untuk mengontrol TRIAC untuk soft starting motor induksi tiga fase $1 \mathrm{~kW}$. Kemudian rancangan soft starting namun menggunakan komponen elektronika daya yaitu SCR. Penelitian tersebut menggunakan komponen elektronika daya yaitu thyristor, dengan penyalaannya dikendalikan oleh mikrokontroller Arduino Nano [5].

Simulasi soft starting pada software khususnya Simulink MATLAB sangat didukung oleh adanya model motor induksi tiga fase [6]. Metode soft starting pada penelitian ini terdiri dari modul SCR soft starting sistem untuk mengontrol tegangan dan arus ke motor secara bertahap, dengan demikian masalah starting motor induksi tiga fase dapat diatasi [7]. Berdasarkan penelitian-penelitian sebelumnya, penelitian ini difokuskan pada analisis soft starting menggunakan anti parallel SCR untuk motor induksi dengan kapasitas $15 \mathrm{~kW}$. Simulasi menggunakan MATLAB versi 2014. Lingkup analisis yang dibahas meliputi arus starting, harmonisa dan konsumsi energi selama starting.

\section{ANTI PARALEL SCR}

Soft starting merupakan suatu metoda starting motor dengan cara mengatur tegangan yang masuk pada motor induksi. Pengaturan tegangan dilakukan dengan memanfaatkan komponen elektronika daya yaitu thyristor [8].

Pertama-tama motor hanya diberikan tegangan yang rendah sehingga arus dan torsi pun juga rendah. Selanjutnya tegangan akan dinaikkan secara bertahap sampai ke tegangan nominalnya dan motor akan berputar dengan kondisi RPM yang nominal [9]. Rangkaian starting metoda soft starting dapat dilihat pada Gambar 1.

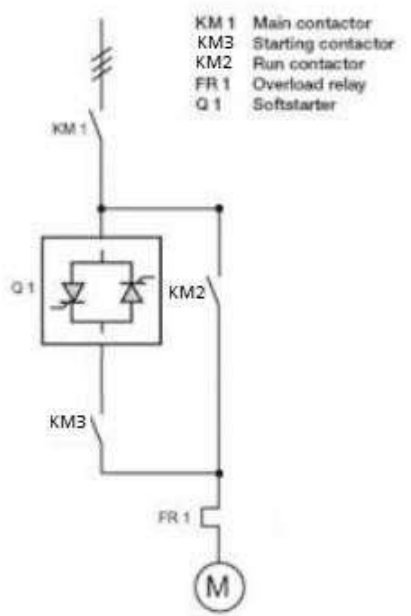

Gambar 1. Diagram starting metoda soft starting [9]

a. Harmonisa pada starting dengan anti paralel SCR

Harmonisa adalah gejala pembentukan gelombang dengan frekuensi perkalian bilangan bulat dari frekuensi dasar sebuah gelombang. Frekuensi yang terbentuk disebut frekuensi harmonisa yang timbul pada bentuk gelombang aslinya sedangkan bilangan bulat pengali frekuensi dasar disebut angka urutan harmonik. Gelombang- gelombang ini menumpang pada gelombang aslinya sehingga terbentuk gelombang cacat yang merupakan jumlah antara gelombang murni sesaat dengan gelombang harmoniknya [10].

Kecacatan gelombang dapat dihitung dengan formula THD. Persamaan 1 adalah formula THD arus dan Persamaan 2 adalah formula THD tegangan.

$T H D_{I}=\frac{\sqrt{\sum_{h=2}^{\infty} I_{h}^{2}}}{I_{1}}$

Dimana, $l_{1}$ dan $I_{h}$ adalah arus RMS komponen fundamental dan arus RMS komponen harmonisa. 
$T H D_{V}=\frac{\sqrt{\sum_{h=2}^{\infty} w_{h}^{2}}}{V_{1}}$

Dimana, $\mathrm{V}_{1}$ dan $\mathrm{V}_{\mathrm{h}}$ adalah tegangan RMS komponen fundamental dan nilai tegangan RMS komponen harmonisa [12].

b. Konsumsi energi selama starting motor induksi

Starting motor induksi membutuhkan waktu sampai motor dapat bekerja secara normal. Proses starting mengkonsumsi energi listrik yang berbeda untuk perbedaan lama waktu start untuk motor induksi. Energi listrik yang dikonsumsi motor induksi selama starting dapat dihitung dengan Persamaan 3.

$E=\frac{1}{1000} P * \frac{1}{3600} t \mathrm{kWh}$

Dimana, $\mathrm{P}$ dan $\mathrm{t}$ adalah daya dalam Watt dan waktu dalam sec.

\section{METODELOGI PENELITIAN}

a. Sepesifikasi dan model komponen pada Simulink MATLAB untuk Simulasi

Spesifikasi motor induksi tiga fase yang diteliti mempunyai kapasitas Daya 15 $\mathrm{kW}$, tegangan $\mathrm{Y} / \Delta: 400 / 230 \mathrm{~V}$, frekuensi: 50 $\mathrm{Hz}$, kecepatan nominal: $1480 \mathrm{rpm}$, Perbandingan Input mekanik terhadap torsi mekanik dengan nilai 0.1 , tipe rotor: sangkar tupai. Spesifikasi motor induksi dari data model mesin asinkron di Simulink MATLAB versi 2014.

Blok SCR/Diode pada Simulink MATLAB versi 2014 mempunyai parameter-parameter resistansi internal (Ron), resistansi snubber (Rs) dan kapasitor snubber (Cs). Nilai default digunakan pada penelitian ini yaitu: Ron = $1 \mathrm{e}-3 \mathrm{ohm}, \mathrm{Rs}=1 \mathrm{e} 5 \mathrm{ohm}$ dan $\mathrm{Cs}=\mathrm{inf}$ farad.

b. Metoda Penelitian

Beberapa model komponen untuk analisis soft starting menggunakan anti paralel SCR yaitu model pulsa penyalaan SCR dan model soft starting. Model pulsa penyalaan SCR untuk sinyal trigger SCR pada rentang sudut fase 1800 - 00 dalam waktu 5 detik, 10 detik, 15 detik, dan 20 detik.

Langkah-langkah penelitian adalah sebagai berikut:
1. Simulasi starting motor induksi 3 fase $15 \mathrm{~kW}$ metoda DOL. Starting motor dengan memberikan tegangan $400 \mathrm{~V}$ ke fase-fase motor.

2. Pembuatan model pulsa penyalaan SCR. Model terdiri dari blok sawtooth generator, blok stair generator, blok pulse generator, blok divide dan blok relational operator.

3. Pengujian model pulsa penyalaan SCR pada SCR. Input SCR yaitu tegangan $400 \mathrm{~V}$, gate SCR dihubungkan dengan model pulsa penyalaan SCR yang diatur dari sudur fase $180^{\circ}$ sampai $0^{\circ}$ untuk melihat hasil tegangan keluaran SCR.

4. Pembuatan model soft starting menggunakan anti paralel SCR 3 fase. Anti paralel SCR 3 fase menggunakan 3 pasang SCR. Setiap pasang diposisikan anti paralel.

5. Pengujian model soft starting untuk beban RL. Beban RL menggunakan blok series RLC branch. Tiga beban $\mathrm{RL}$ dihubung bintang, nilai $\mathrm{R}=1 \mathrm{ohm}$ dan $L=1 \mathrm{mH}$. Soft starting diseting dalam waktu 2 detik dengan 10 tahapan trigger SCR dari sudut fase $126^{\circ}$ sampai $0^{\circ}$.

6. Simulasi soft starting pada motor induksi 3 fase $15 \mathrm{~kW}$. Durasi waktu simulasi untuk starting adalah 5 detik, 10 detik, 15 detik dan 20 detik.

a. Waktu starting 5 detik, pulsa penyalaan SCR diatur secara bertahap (6, 10, dan 20) antara sudut fase 1800 sampai 00 .

b. Waktu starting 10 detik, pulsa penyalaan SCR diatur seperti point a.

c. Waktu starting 15 detik, pulsa penyalaan SCR diatur seperti point a.

d. Waktu starting 20 detik, ulsa penyalaan SCR diatur seperti point a.

7. Analisis hasil soft starting untuk arus starting, harmonisa, dan energi yang dikonsumsi motor selama starting.

\section{HASIL DAN PEMBAHASAN}

a. Starting motor induksi 3 fase metode DOL

Gambar 5 adalah rangkaian starting metoda DOL untuk motor induksi tiga fase $15 \mathrm{~kW}$. Rangkaian terdiri dari blok mesin asinkron SI units, dan blok sumber 
tegangan $\mathrm{AC}$ satu fase yang disusun hubung bintang menjadi sumber AC tiga fase. Sumber AC tiga fase seimbang dengan magnitude yang sama dan selisih antar fase 1200, tegangan antar fase 400 $\mathrm{V}$, dan frekuensi $50 \mathrm{~Hz}$.

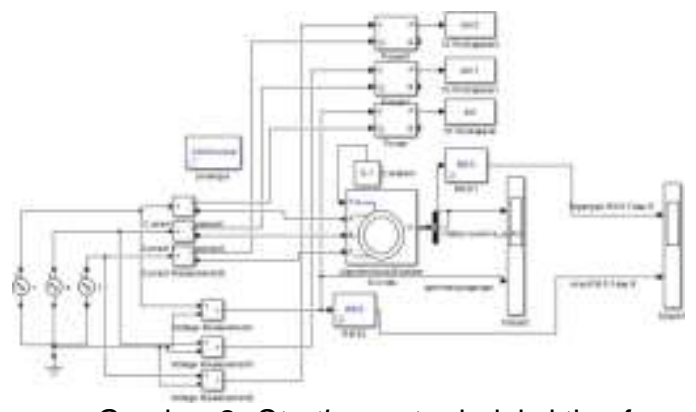

Gambar 2. Starting motor induksi tiga fase metode DOL

Sumber tegangan $400 \mathrm{~V}$ diberikan pada saat start sehingga terjadi lonjakan arus starting yang sangat tinggi. Lonjakan arus starting sebesar 299.7 A sebelum mencapai arus nominal motor $40 \mathrm{~A}$, ditunjukkan pada Gambar 4 bagian atas. Gambar 4 bagian bawah adalah tegangan fase ke netral yang terukur yaitu $230 \mathrm{~V}$.
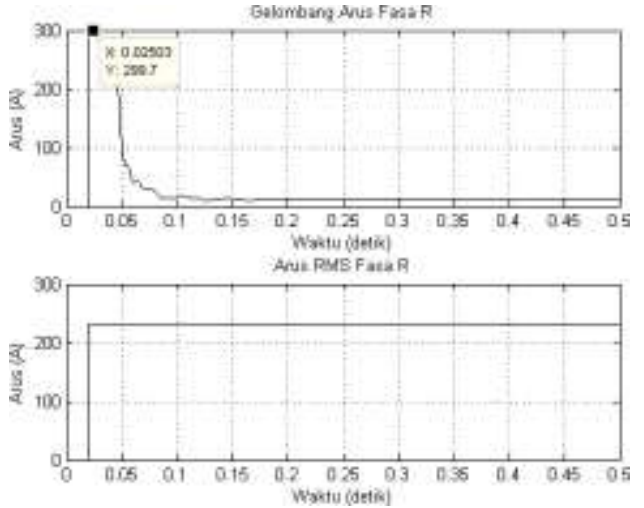

Gambar 3. Arus dan tegangan fase $\mathrm{R}$ metoda DOL.

b. Model pulsa penyalaan SCR untuk anti paralel SCR

Pembuatan model pulsa penyalaan SCR menggunakan blok sawtooth generator, blok stair generator, blok divide, blok pulse generator dan blok relational operator. Model pulsa penyalaan SCR ditunjukkan pada Gambar 4

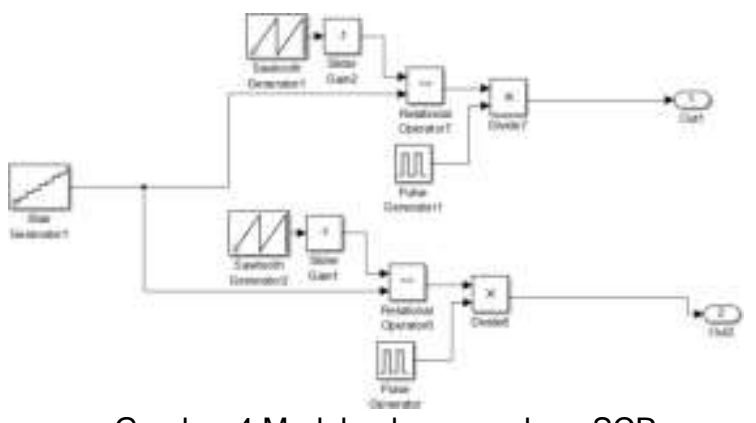

Gambar 4 Model pulsa penyalaan SCR

Prinsip kerja model pulsa penyalaan SCR yaitu, pada saat nilai tegangan referensi lebih besar dari tegangan carrier yang dihasilkan oleh sawtooth generator maka keluaran blok relational operator akan bernilai high. Namun saat tegangan referensi bernilai lebih kecil dari tegangan carrier, maka keluaran blok relational operator akan bernilai low. Variasi nilai high dan low tersebut merupakan keluaran sinyal Pulse Width Modulation (PWM) dari blok relational operator. Sinyal PWM tersebut berfungsi sebagai pulsa penyalaan SCR.

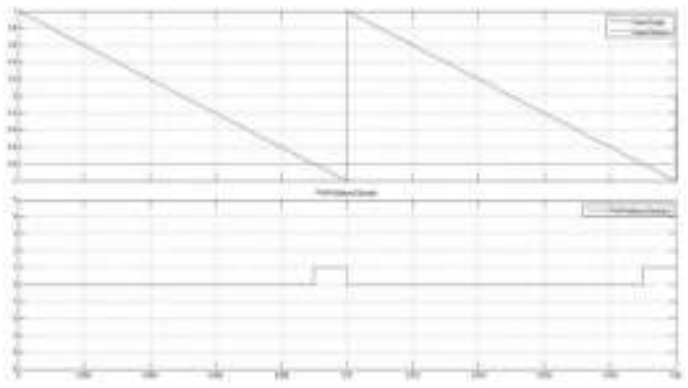

Gambar 5. Sinyal-sinyal pulsa penyalaan SCR

Gambar 5 bagian atas adalah tegangan carrier yang dihasilkan oleh sawtooth generator. Gambar 5 bagian bawah adalah pulsa penyalaan SCR berupa PWM yang memiliki frekuensi sebesar $100 \mathrm{~Hz}$. Perubahan tegangan referensi dari -1 sampai dengan 1 , menghasilkan sudut fase penyalaan SCR dari $180^{\circ}$ sampai dengan $0^{\circ}$. Tegangan referensi sebesar -0.8 , menghasilkan sudut fase penyalaan SCR yaitu $162^{\circ}$.

Pulsa penyalaan SCR dari blok relational operator dibagi dengan sinyal PWM blok pulse generator menggunakan blok divide menghasilkan sinyal trigger SCR untuk siklus positif maupun negatif seperti ditunjukkan pada Gambar 6. 


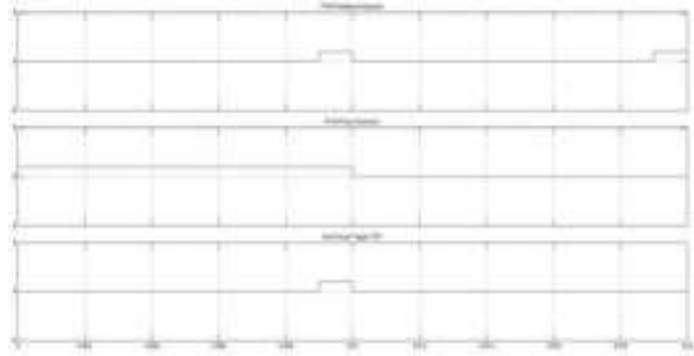

Gambar 6 Pusal penyalaan SCR untuk siklus positif

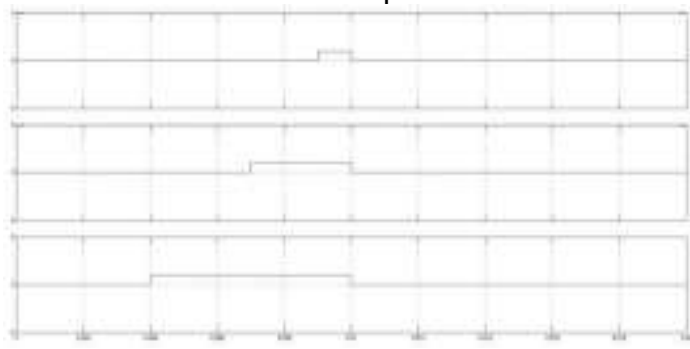

Gambar 7 Sinyal trigger SCR dengan sudut fase penyalaan $162^{\circ}, 126^{\circ}$ dan $72^{\circ}$

Gambar 7 adalah hasil pulsa penyalaan SCR untuk tegangan referensi dari -1 sampai 1. Dalam rentang tegangan tersebut dipeoleh sinyal triger SCR dengan sudut penyalaan antara 1800 sampai 00.

c. Pengujian soft starting untuk beban RL.

Rangkaian simulasi soft starting menggunakan anti paralel SCR untuk beban RL ditunjukkan pada Gambar 8. Rangkaian terdiri dari: model soft starting, blok series RLC branch dan model pulsa penyalaan SCR. Rangkaian dilengkapi blok scope untuk melihat hasil pengukuran variabel-variabel sistem seperti tegangan, arus, dan THD.

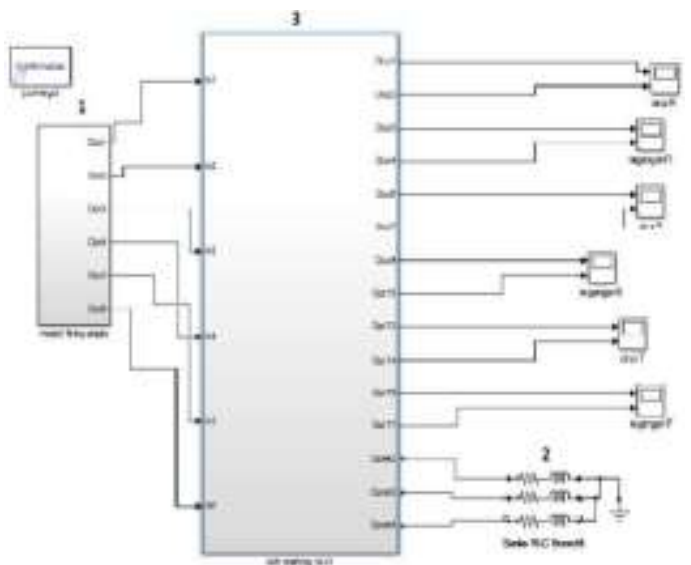

Gambar 8. Soft starting untuk Beban RL

Blok model soft starting pada Gambar 8 ditampilkan pada Gambar 9 . Model soft starting terdiri dari blok sumber tegangan AC satu fase 3 buah, blok SCR/Diode 3 pasang, setiap pasang dirangkai secara anti paralel.

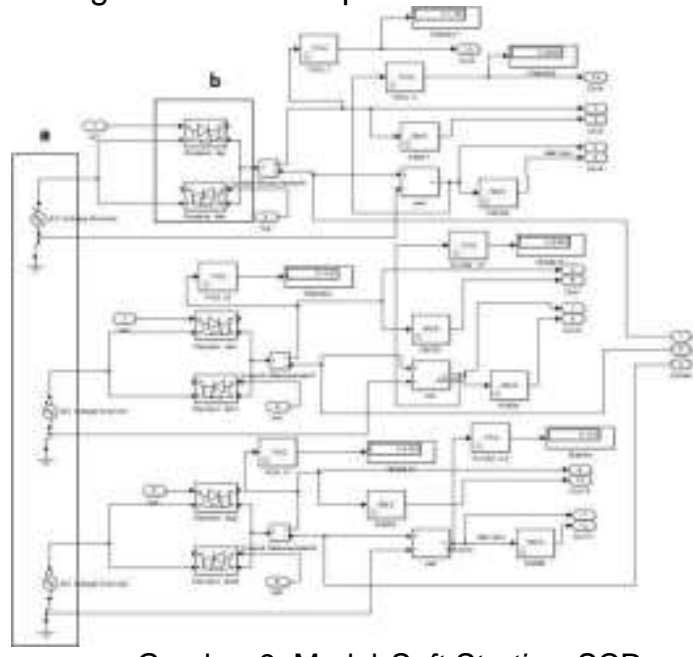

Gambar 9. Model Soft Starting SCR

Tabel 1 menunjukkan hasil simulasi soft starting untuk beban RL. Sudut fase untuk trigger SCR dirubah dari sudut fase 1620 sampai 00 dalam 10 tahap. Perubahan sudut fase menghasilkan tegangan dan arus pada beban RL semakin besar apabila sudut fase dari pulsa penyalaan SCR untuk triger SCR semakin kecil. Perubahan terjadi secara linear dan berbanding terbalik.

Tabel 1. Hasil simulasi soft starting beban $R L$

\begin{tabular}{|r|r|r|}
\hline $\begin{array}{c}\text { Sudut } \\
\text { Penyalaan ( }{ }^{\circ}\end{array}$ & $\begin{array}{c}\text { Tegangan RMS } \\
\text { (V) }\end{array}$ & $\begin{array}{c}\text { Arus RMS } \\
\text { (A) }\end{array}$ \\
\hline 162 & 8,8 & 20,25 \\
\hline 144 & 33,8 & 52,5 \\
\hline 126 & 67,84 & 90,12 \\
\hline 108 & 105,2 & 128,5 \\
\hline 90 & 141,2 & 163,6 \\
\hline 72 & 172,4 & 192,4 \\
\hline 54 & 196,4 & 213 \\
\hline 36 & 211,8 & 225,1 \\
\hline 18 & 219,3 & 230 \\
\hline 0 & 219,3 & 230 \\
\hline
\end{tabular}

d. Simulasi soft statring pada motor induksi 3 fase

Rangkaian starting seperti Gambar 8 dengan mengganti beban $R L$ dengan model motor induksi tiga fase $15 \mathrm{~kW}$, seperti ditunjukkan pada Gambar 10. Motor induksi $15 \mathrm{~kW}$ disuplai oleh sumber tiga fase melalui rangkaian soft starting dengan anti paralel SCR. 


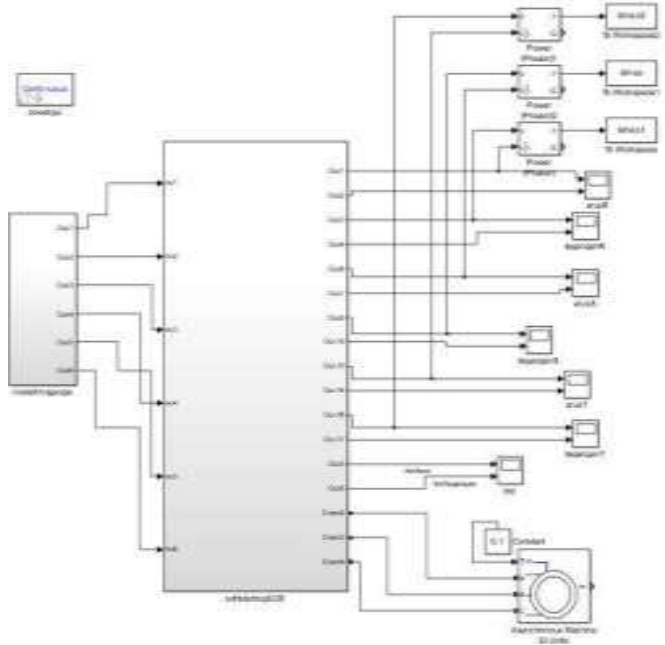

Gambar 10. Model soft starting motor Induksi 3 Fase

Gambar 11 adalah grafik arus starting hasil simulasi soft starting pada motor induksi 3 fase. Durasi starting 5, 10, 15 dan 20 detik, masing-masing untuk 5, 10 dan 20 tahap pengaturan pulsa penyalaan SCR untuk trigger SCR. Hasil simulasi menunjukkan arus starting paling rendah terjadi untuk durasi starting 20 detik dan arus starting tertinggi terjadi pada durasi starting 5 detik untuk semua tahap starting. Tahap starting untuk semua durasi starting menghasilkan penurunan arus starting untuk tahap yang lebih banyak. sebagai contoh durasi waktu starting 5 detik untuk 20 tahap menghasilkan arus starting yang lebih kecil 265.8 A dibandingkan dengan 5 tahap 288.1 A. Hasil simulasi soft starting pada motor induksi tiga fase $15 \mathrm{~kW}$, arus starting terendah dihasilkan dari durasi starting 20 menit dengan pengaturan pulsa penyalaan SCR untuk trigger SCR sebanyak 20 tahap yaitu $92.55 \mathrm{~A}$.

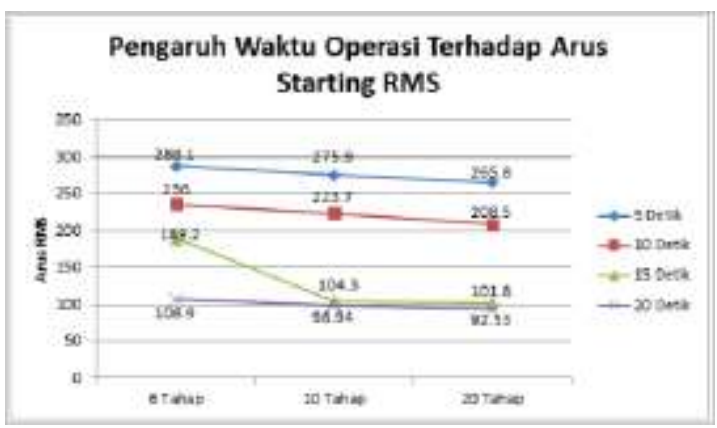

Gambar 11 Perbandingan durasi waktu dan tahap starting terhadap arus starting
Tahapan tegangan hasil dari soft starting menggunakan anti paralel SCR mengakibatkan munculnya hormonisa tegangan dan arus pada motor. Harmonisa muncul dari hasil pemotongan gelombang tegangan sinus oleh SCR selama durasi starting. Harmonisa dalam besaran THD terukur dalam selang waktu starting. THD tegangan untuk semua durasi waktu dalam 20 tahap starting ditunjukkan pada Gambar 12. Hasil pengukuran THD yang ditunjukkan pada Grafik Gambar 12 menghasilkan nilai THD tinggi pada saat pulsa penyalaan SCR untuk trigger SCR pada beda fase tahap 2 dari 20 tahap untuk semua durasi starting. Secara nilai THD tegangan selama durasi starting masih dianggap rendah karena kurang dari 5\% (standar IEEE 519-1992 untuk tegangan rendah).

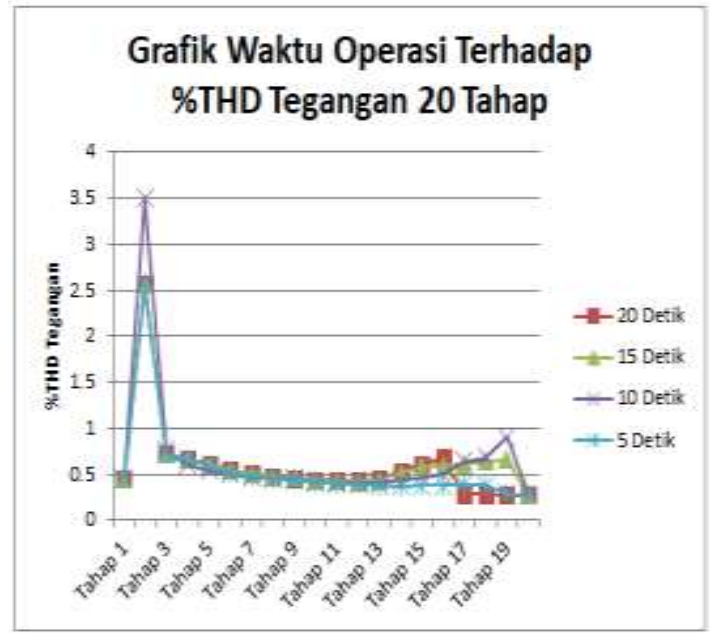

Gambar 12 Perbandingan THD tegangan pada berbagai durasi waktu starting untuk 20 tahap

Hasil simulasi soft starting motor tiga fase $15 \mathrm{~kW}$ ditinjau dari konsumsi energi selama durasi waktu dan tahap starting ditunjukkan pada Gambar 13. Tahapan starting tidak banyak berpengaruh pada konsumsi energi selama starting, tetapi konsumsi energi sangat dipengaruhi oleh durasi waktu starting. Untuk semua tahap, durasi waktu starting semakin lama, energi yang dikonsumsi semakin besar. Konsumsi energi untuk durasi waktu 20 detik lebih tinggi dari 15, detik, 10 detik dan 5 detik secara berturut-turut. 


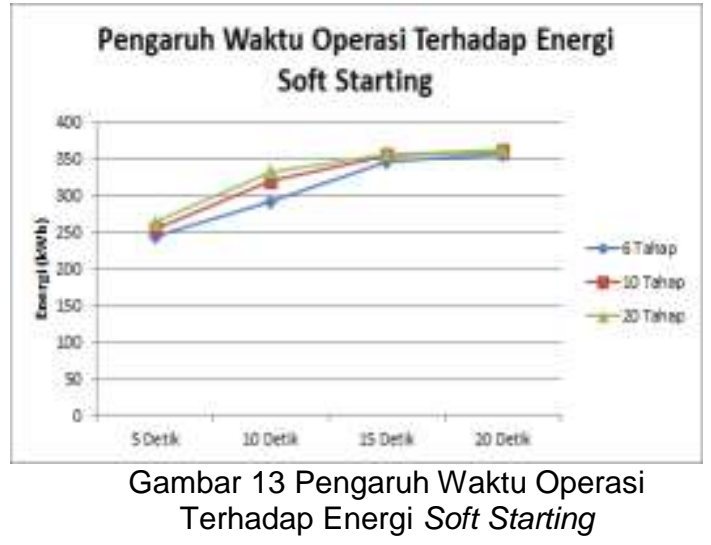

\section{KESIMPULAN}

Soft starting menggunakan anti paralel SCR pada motor induksi tiga fase $15 \mathrm{~kW}$ dapat mengurangi arus starting secara signifikan dari 299.7 A metoda DOL menjadi 92.53 A metoda soft starting menggunakan anti paralel SCR untuk durasi waktu 20 detik dengan 20 tahap starting. Soft starting selama durasi starting menghasilkan harmonisa pada tegangan dan arus motor yang terukur dengan besaran THD. THD tegangan selama durasi waktu starting dipengaruhi oleh tahap-tahap starting. Untuk 20 tahap starting, tahap 2 memberikan konstribusi THD tertinggi selama starting, tetapi THD kecil bila dilihat dari standar IEEE 519-1992 untuk tegangan rendah. Konsumsi energi selama durasi starting, sangat dipengaruhi oleh lama durasi starting. Semakin lama durasi starting energi yang dikonsumsi semakin besar.

\section{REFERENSI}

[1] T.N. Imamudin, "Perancangan Soft Starting pada Motor Induksi 3 Fasa Menggunakan Mikrokontroler Atmega328". Tugas Akhir. Teknik Elektro. Institut Teknologi Sepuluh Nopember. Surabaya, 2017.

[2] D.H. Riyadi, "Perancangan Modul Soft Starting Motor Induksi 3 Fase dengan ATMEGA 8535. Transmisi," 12(4),160167, 2010.

[3] A.B. Priahutama, T. Sukmadi, I. Setiawan, "Perancangan Modul Soft Starting Motor Induksi 3 Fase dengan ATMEGA 8535. Transmisi" 12(4),160-167, 2010.

[4] R. Ardiansyah, I.M.A. Nrartha, I.M.B Suksmadana, "Perancangan Soft Starting Pada Motor Induksi Tiga Phase Menggunakan Mikrokontroller ATMEGA328". Dielektrika, 2(2), (91-96). 2015
[5] A. Saputra, Syukriyadin, M. Syukri, "Perancangan Rangkaian Pengasutan Soft Starting Pada Motor Induksi 3 Fasa Berbasis Arduino Nano". Karya IImiah Elektro, 2(4), (45-51), 2017.

[6] K. L. Shi, T. F. Chan, Y. K. Wong, S. L. Ho,. "Modelling and simulation of the three-phase induction motor using SIMULINK". Int. J. Electr. Eng. Educ. doi: 10.7227/IJEEE.36.2.6, 1999.

[7] L. Quan, X.., Wang, J., Zhou,. "Research and Simulation of SCR Soft-Start Asynchronous Motor". ICAEES. (11441148), 2015.

[8] A. Sugiharto. "Soft Softdan Dynamic Braking Pada Motor Induksi Tiga Fasa Menggunakan Mikrokontroler AT89S51". Skripsi. Universitas Bengkulu. Bengkulu, 2014.

[9] Y.R. Fauzi, "Perancangan Soft Starting pada Motor Induksi 3 Fasa Menggunakan Mikrokontroler Atmega328". Tugas Akhir. Teknik Elektro. Institut Teknologi Sepuluh Nopember. Surabaya, 2017.

[10] N. Tribuana, \& Wanhar, ."Pengaruh Harmonik pada Transformator Distribusi" 1999. https://www.elektroindonesia.com.

[11] N. Mohan, T.M..Undeland, W.P. Robbins, "POWER ELECTRONICS (2 ed.). John Wiley \& Sons, Inc. Rashid, M. Power Electronics. (2001). India : Academic Press,. 1995 